\title{
Dynamic Modularization Management of Perishable Products in Supply Chain Based on Information Stratification
}

\author{
Lu Liu, ${ }^{1, *}$ Lei Wang ${ }^{2}$, Xinlei Liu ${ }^{1}$, Huiqi Zhu ${ }^{1}$, and Hua Wang ${ }^{3}$ \\ ${ }^{1}$ College of Transportation, Ludong University, Yantai 264000, China. \\ ${ }^{2}$ Neusoft Research Istitute, Dalian, 116000, China \\ ${ }^{3}$ College of Engineering, University of Kentucky, Kentucky 40503, USA
}

Received 11 October 2017; Accepted 17 January 2018

\begin{abstract}
The qualities of perishable products are significantly influenced by the environment during the circulation process, and environmental factors have a crucial effect on the decay of perishable products. Timely risk control can ensure the safety of perishable products when environmental information in circulation is completely collected. In order to comprehensively collect the environmental information of the perishable products in the supply chain, this study presented a method that extracted the cold chain information according to the independent category and constructs to establish the information dynamic record data collection method and the information integration framework model. Based on the information that could be independently extracted from the cold chain, this study proposed that the data collection of dynamic recording should be conducted and the module framework of information integration should be constructed. By designing and planning the individual module of cold-chain circulation information of perishable products, dynamic data collection and information integration framework were shaped to classify and stratify the key information, and aquatic products in the cold chain were taken as an example to verify the effectiveness and accuracy of the module. Results indicate that $89 \%$ of the integrated processing of environmental information can be achieved through the independent module processing of perishable products and dynamic management of information stratification. Meanwhile, information modularization, rate of stratification coverage, and accurate estimation of the shelf life of perishable products exhibit a positive correlation. To some extent, the proposed method provides references for the coldchain risk management and accurate estimation of the shelf life of perishable products.
\end{abstract}

Keywords: modularization, perishable products, management of supply chain, risk identification, dynamic design

\section{Introduction}

The supply chain of perishable products in the context of possessing the features of supply-chain information requires the collection of information related to the influencing qualities of perishable products. One of the most crucial factors is the environment and operation information, which influence the quality and safety of perishable products and their shelf life. Environmental information exerts its influence on the quality decay rate of perishable products, whereas operational information has a direct effect on the safety of the processing, storage, and transportation of perishable products. Environmental and operational information combined with the general information of the supply chain leads to a complex information of perishable products in the supply chain, thereby shaping a multilevel, multi-dimension network structure. This kind of complexity poses problems, such as difficult evaluation of safety and uneasy management of perishable products in the supply chain. With respect to these problems, modern traditional enterprises still lag behind in management and have outdated information and methods. The limited information sharing contributes to the difficulty in dealing with the complex multi-dimensional information regarding managing

\footnotetext{
*E-mail address: Liululd@126.com

ISSN: $1791-2377$ @ 2018 Eastern Macedonia and Thrace Institute of Technology. All rights reserved. doi:10.25103/jestr. 111.15
}

perishable products in the supply chain. Therefore, under these circumstances, this study presents a mathematical model of dynamic modularization management of perishable products in the supply chain based on information stratification

The key information of perishable products in the supply chain is identical. This kind of identity can be used to describe and record the information of the environment and operation in detail when perishable products in the supply chain are in the process of circulation. The basic environmental parameters include temperature and humidity. The basic operational parameters include working procedures of process, storage, and transportation in detail. The information is integrated into the entire data classification and can be processed and presented in the data structure. During periodic and eventual analysis and evaluation of the secure qualities of perishable products, the preceding key information mentioned serves as the underpinning of the data.

According to the theory of information transfer, information gap can form in the supply chain during message passing. The entropy evaluation method of network structuring can be combined with different topics to proceed with key node screening. Gray relational grade theory can be utilized to determine the degree of association between upstream and downstream. Based on NF-TOPSIS, rational key node extraction can ensure that supply-chain enterprises share the information between nodes to form the standard 
module of information management. Thus, the overall shared framework among enterprises of perishable products in the supply chain is constructed, thereby taking the shape of a flexible integration and process mode of information modularization to accomplish the dynamic modularization management of supply-chain information. On this basis, enterprises can increase the overall supply-chain transparency by sharing information with each other, thereby achieving the overall safety evaluation and risk management of perishable products, promoting the overall efficiency of supply-chain coordination, and affording a powerful approach to realize resource optimization and integration of supply chain in the large scale.

The design of standard modularization will influence safety factor combinations of perishable products and constitute a separate subsystem with specific functions. Information transfer and sharing occur in all links of this subsystem as a common module. Meanwhile, standard modularization enables itself to interact with internal private modules of independent enterprises of the supply chain to construct a new and separate system and ensure that the internal management information of enterprises is integrated and decisions are supported. Private modules can allow enterprises to organize and manage internal information and resources, including the analysis of internal operational costs of business transfer. Furthermore, enterprises can obtain the shared key information of perishable products through the modules and use this information for their safety analysis, followed by risk identification of the entire supply chain. Modularization management of the supply chain can enable the related analysis of the quality and environment attributes of perishable products because, on the one hand, it can ensure the timely risk control of supply-chain safety. On the other hand, the information barrier can be reduced or removed to ensure optimal management from the perspective of the overall supply chain resource, thus lowering the cost and reducing food safety incidents.

Therefore, with respect to the crucial factors that can affect supply-chain management of perishable products, this study is conducted to design the functions of standard modules to realize the independent management of key information. Connections among all kinds of information have been closely established, and the network structure of overall information integration has been developed. The standard module design runs through the entire supply chain, thereby breaking the information conflicts in every link among enterprises and eventually maintaining the information managed in a unified platform.

\section{State of the art}

Thus far, regarding the supply-chain management of perishable products, which is mainly referred to as the cold chain applied to perishable products, numerous works have already been conducted by researchers. The cold chain is a series of low-temperature control processes, ranging from the supply of raw materials, production, processing, packaging, inventory, and transportation to the eventual consumption. The essence of the cold chain is a particular supply-chain system controlled by temperature[1]. Therefore, the completeness and accuracy of temperature information are crucial criteria for testing energy efficiency.

Barrrier and Ruddich proposed the cold-chain concept in 1894 , and the research on perishable products originated with Whitin[2,3]. Since then, many scholars and researchers have conducted comprehensive research in this field. Nahmias[4] summarized previous research before the 1980s and divided perishable products into fixed and random life cycles. This study mainly focused on the products of the random life cycle. Particularly, the safety and risk management of perishable products in the supply chain were of considerable importance to its shelf life[5,6]. In 2011, Cheri Speier[7] and other researchers proposed a multimethod approach that could establish a safer supply chain of perishable products than the traditional method. However, this multi-method approach lacked initiative concerning the supply-chain design, and the module cost would significantly increase due to a few measures. Based on RFID, G. Prakash[8] and other researchers proposed a kind of management system of movable cold-chain storage with the advantage of reducing monitoring work, process control, and wastes. However, this system could only monitor the temperature index and is not conducive to risk monitoring and control of the supply chain and the precise control of risk nodes.

By contrast, the module presented in this study is not costly. The initiative in the supply-chain design is also fully considered. Moreover, three information modules, namely, operation, temperature, and environment, can be simultaneously monitored to ensure that the unsolved problems of previous researchers can be better dealt with. As for the supply chain, good risk management of perishable products is unusual. If the quality guarantee period is overrated, then the quality of the product would be reduced. Consequently, food wastes will increase. Thus, this phenomenon is regarded as a serious problem[9]. Therefore, risk identification of perishable products in the supply chain is a necessary and indispensable technology.

In 2017, David Bogataj proposed that the combination of a kind of intelligent wireless sensor and such means of transportation as container cars or vessels, which is equivalent to an extension based on MRP, could constitute a network to control the supply risk to enable the users to monitor the quality of products. Simultaneously, combinations of the Internet of Things and different kinds of intelligent containers are constantly emerging[11,12], thereby strengthening the visualization of the entire supply chain to monitor the supply-chain risk. These methods are usually used during the transportation of goods, which could not properly record operational nodes and operational and environmental information during the process.

A multilevel, multi-dimension data network structure was formed through the collection of environmental, temperature, and operational information in the supply chain of perishable products. Reducing the cost and conducting risk identification, control, and management in the supply chain is relatively easy by modularization. From the perspective of design, modularization is not only a flexible and highly efficient approach to improve the competitiveness of supplychain enterprises but also a design method that could be integrated with the flexibility of the supply chain[14]. The design of modularization is now mostly used for the assembly of products[15,16] to reduce costs and improve reliability and management. The design of modularization can also promote the green supply-chain-oriented development and reduce wastes[15-17]. The current design is mainly aimed at the production[18], assembly, and location of hub nodes[19] and logistics technical equipment[20]. In this study, a novel idea of combining modularization with the entire supply chain was proposed. Meanwhile, the model was used to identify and control the 
risks in the supply chain of perishable products to increase their shelf life.

The remainder of this study is organized as follows. Section 3 establishes a description of the information modularization structure of perishable products in the supply chain and constructs a framework of dynamic information stratification. Section 4 discusses the framework of independent modular processing and collects experimental information based on the circulation process of aquatic products by conducting complete and effective information recording and integration. Section 5 summarizes the conclusions.

\section{Methodology}

On the basis of ensuring the quality and safety of perishable products, the information modularization structure of the supply chain develops into a kind of sharing system, with flexible structure and integrated information. The modular structure, which takes products as the main line, can design independent and standardized functional modules. Each group of structural units alone can be represented as independent modules. Between these modules, an integrated and holistic framework that is related to each other is established. The modular design can describe the operation, environment, technology, and product application of the entire supply chain. Data can be extensively obtained from the vertical direction of information, which shows the cooperation and integration of supply chains. In the horizontal direction of information, the completeness of data which represents the integration of supply chain, can be analyzed. The supply chain has a distinguishing feature in which qualities of perishable products significantly vary over time and exhibit a kind of irreversible quality decay. The information of perishable products in the supply chain demands data with high integrity and completeness. Moreover, the relationship between information is closely related to each other, particularly enterprises, operating process, and environment. In this case, the designed module must be transferable and standardized and can ensure the completeness of the entire supply chain information, thus forming a full-chain information integration framework under the same structure. Hence, the circulation of frozen mackerel fish pieces in the supply chain is taken as an example in this study to conduct modeling and design concerning the evaluation model of perishable product qualities.

\subsection{Dynamic design of the supply-chain module of perishable products}

The standard module includes the following three tasks: configuration, cooperation, and coordination, which work together in the supply chain management system to ensure the formation of standardized information transmission and sharing. The nonstandard module is set as the internal module unit of the enterprise, which can ensure flexible information processing and management. This study designed standard and nonstandard modules according to the features of perishable products and the demands of supplychain management. The standard module, namely, public module, demands information sharing with the entire supply chain to obtain complete information support, including the information of enterprises, real-time location, product information, and real-time environmental description, Meanwhile, nonstandard module, which is also known as private module, whose information is private and not shared among enterprises, including operation flow, internal management, cost accounting, and other private business modules, establishes the dynamic connection among modules through the entire module list. The variation of each sub-module with its specific content does not affect the overall information processing mode, thereby realizing the dynamic and flexible framework of the supply chain information integration. The operation process module records the operation of perishable products in detail via the enterprise as the main body. As a major link mode connecting standard modules, the recorded key codes of this module are used to establish the information connection among modules with identical standards. The productprocessing code sets up a kind of connection with the standard module of product information, environmental attribute number with the standard module of environment, location module number with the standard module of geographical location, and enterprise number with the standard module of enterprise information. Moreover, the three standard modules used for information sharing of perishable products in the supply chain establish the overall connection of information via the operation flow module, which is independently set up within the enterprise. Through the enterprise standard module, the management module inside the enterprise, which is built based on the entire information connection, can manage the enterprise as a whole and simultaneously realize information transmission and supply chain sharing.

Taking product information as the core, it runs through information management of all perishable products in the supply chain, provides timely evaluations of the supply chain security state according to the quality evaluation rate, and conducts real-time supply-chain risk identification and management. The standard module of environmental information is used to describe the environmental parameters in the process of product circulation. According to the features of perishable products, time-temperature data are extracted solely in the environmental information module to describe the product environment in this study. The standard module of geographical location can be used to obtain the information of real-time displacement. By extracting the private operation module information, the residence time of the products in a specific location can be calculated, thereby providing a location analysis basis for evaluating perishable product qualities and conducting risk management and control. In practical application, different kinds of parameters can be established to collect environmental data according to the specific requirements of perishable products Combinations of environmental and displacement data are significantly essential in conducting the analysis of perishable product qualities and are crucial for information sharing to ensure effective supply chain assessment. The standard module of product information is used to share information provided by the supply chain.

The framework, where information among modules is connected and integrated, provides the supply chain the kind of information that comes from the changes of operation, environment, and displacement with the passage of time. The module can record the effective analysis of product qualities in the state of timing sequence and provide the shelf-life prediction value at a particular supply-chain node. 


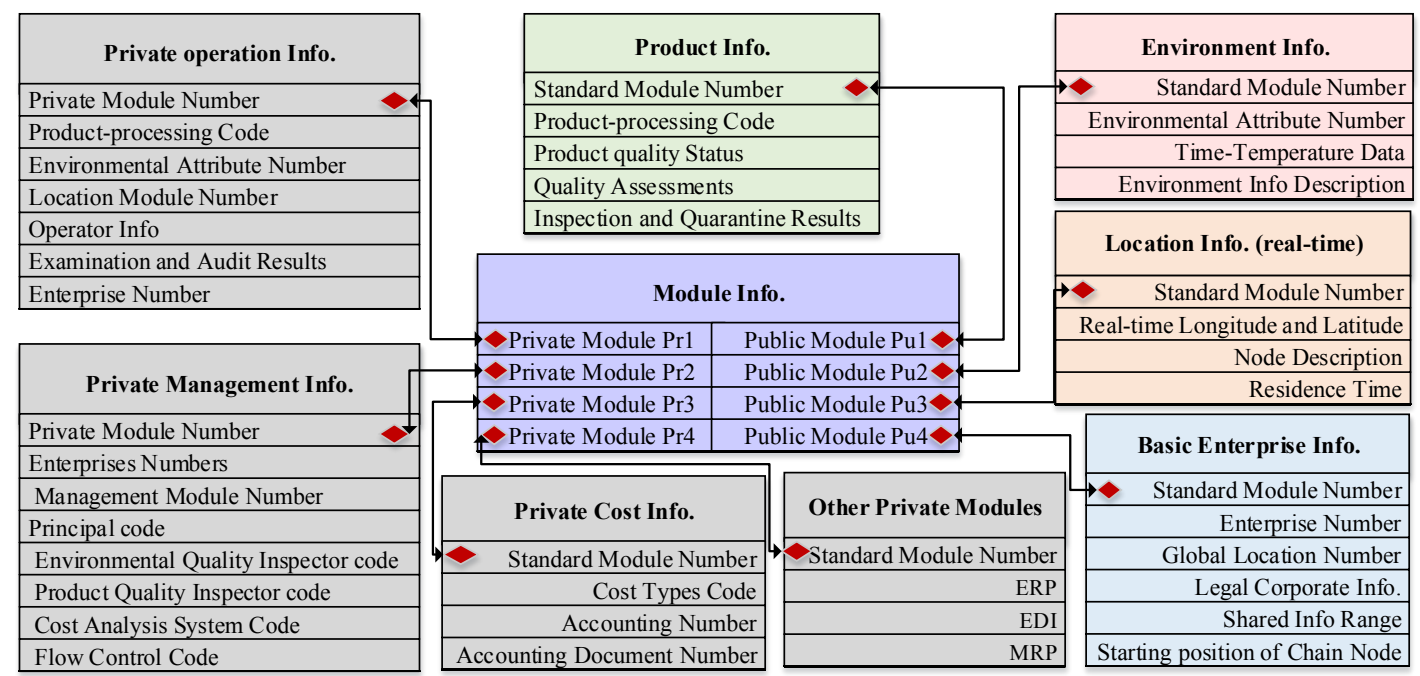

Fig. 1. Pssociation diagram of standard and nonstandard modules

\subsection{Interface design of the supply-chain module of perishable products}

The interface is supposed to be programmed according to the information connection boundary defined by the private and public modules. This kind of information connection or interaction can arise between machine software and hardware from external equipment or among the operators and can be an integration of multiple sources of information. Through interface design, the standard of information extraction and interaction between modules is set, and private and public modules are connected. Consequently, sharing and uploading of public information can be realized and internal management and integration of private information are achieved.

Based on the interface protocol, the data structure is normalized and unified, and the information integration channel between modules is built. Thus, functional module structure and complete information integration are ultimately combined. The flowchart of modularized information delivery is shown in Fig. 2. Taking the full-time attribute of perishable product supply chain as the criterion, the horizontal transfer of information flow represents the circulation process of supply-chain nodes, including raw materials, processing, warehousing, transportation, and distribution. Meanwhile, the vertical transfer of information flow shows the sharing and management of supply-chain information, including the shared information uploaded through standard modules and internal information of enterprise management through private modules. In the diagram of information modularization framework, full information entry and sharing of the supply chain are displayed as the horizontal transfer of information, which reflects the extent of information integration of perishable product lifecycle. Information gathering and integration can be regarded as the vertical transfer information, which reflects the level and depth of supply-chain management. The depth of management can not only effectively manage the behavior of perishable product circulation with supplychain information but also analyze the causes of supplychain management behavior to formulate corresponding measures and conduct comprehensive management strategies.

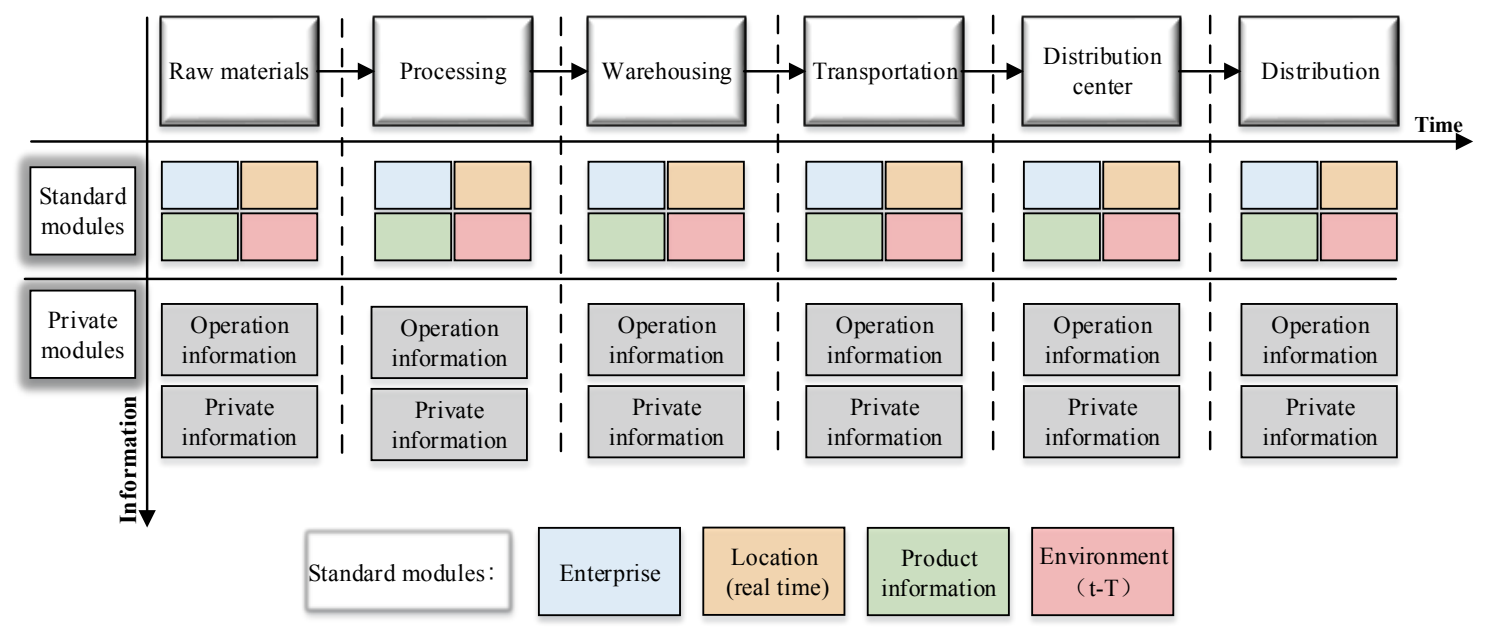

Fig. 2. Information-transmission framework of perishable product supply chain

The standard module is the main body of the information uploaded by each node in the supply chain, including the major information involving enterprises, real-time geographical location, product feature information, and specific description of the circulation environment. Owing to information sharing of the standard module, the supply chain of perishable products has its own complete framework of information integration, through which the entire circulation information is shared. Moreover, a major information basis 
for evaluating the quality grade, risk identification, and processing of perishable products is provided.

With the shared information flow of standard modules, internal management and procedures of enterprises are

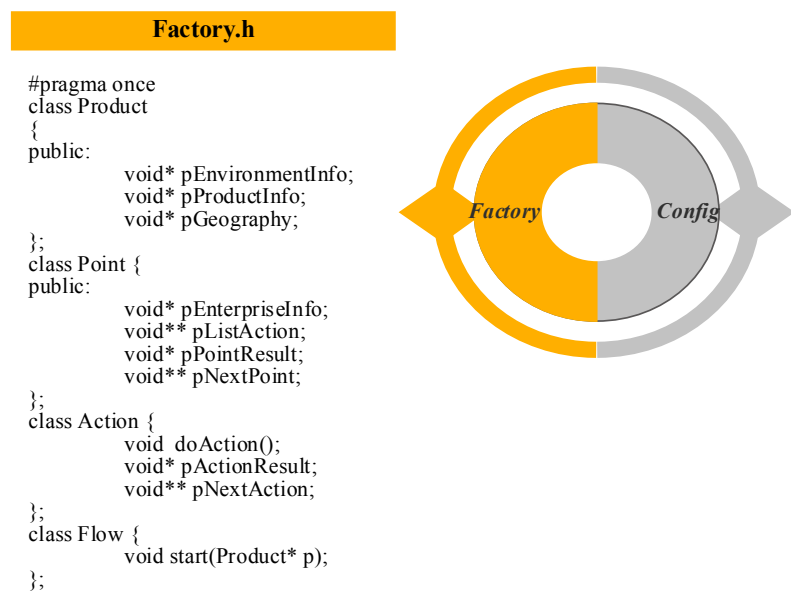

Fig. 3. Framework of the interface standard diagram

\subsection{Information extraction and stratification of} perishable products in the supply chain

In the framework of information integration between public and private modules, the supply chain utilizes the interface protocol to conduct full-chain information collection and sharing. Information stratification is a kind of classification and collection based on information connection. In this way, the form with the key information can be separately summarized, thereby facilitating easy information analysis and mining. The way in which information is stratified is optimized by connecting private modules of each supplychain node. The module interface connects and manages the supply-chain nodes between standard (i.e., private modules) and nonstandard modules (i.e., public modules).

based on the basic full-connection framework of the supply chain. The key information can be handled using logical stratification and can be recorded in a complete summary form due to full-chain information sharing of the supply chain. The key information of the form is also extracted based on the sequence of information sharing and uploading in the supply chain. The form is the information stratification structure based on time series. The information of each form contains the time attribute.

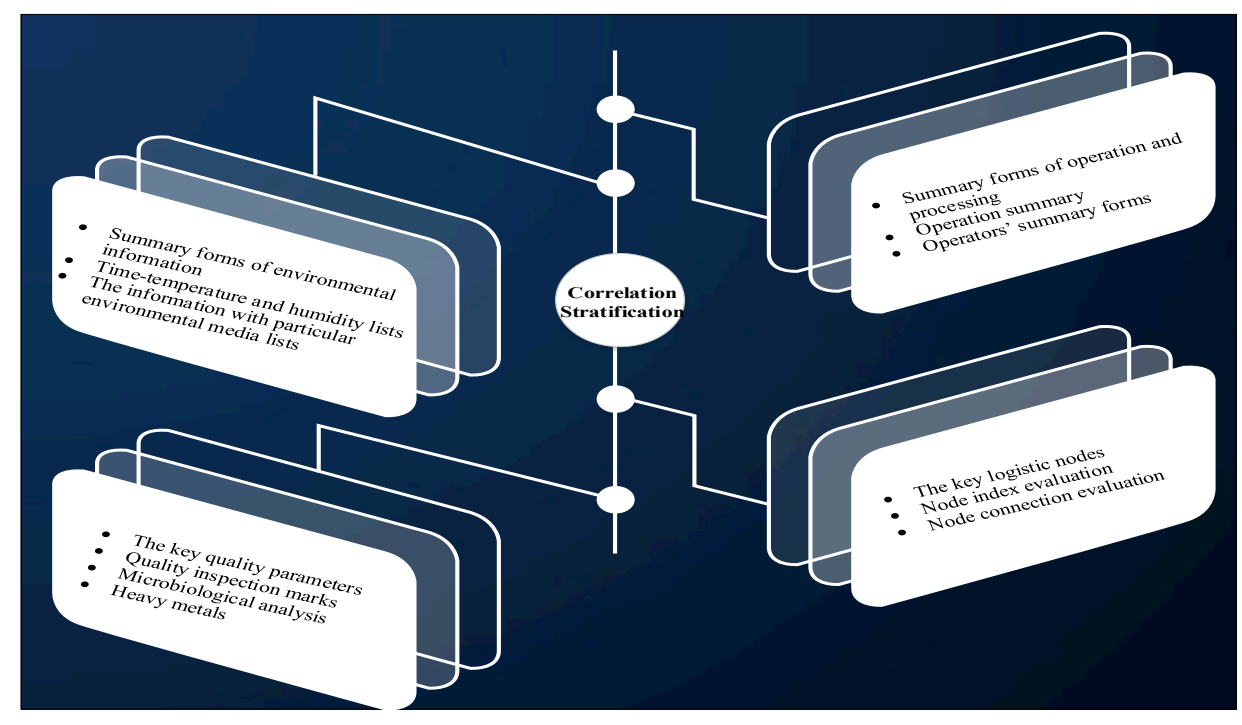

Fig. 4. Stratification of supply-chain information

Stratification of the key information comprises processing, environmental information, inspection information, and quality information. Processing is the key standard used to determine whether the operation of perishable products is appropriate and secure and is the crucial reference point for optimizing the supply-chain flow. Processing information stratification includes such summary information as detailed operation processes and operators and can realize the following functions: (1) determining the security of the entire operation; (2) formulating the CCP control point, which is a crucial criterion; and (3) matching the information between operators and processes. Through the correlation between the two kinds of information, a clear division of power and responsibility is drawn to identify specific operational steps and operators involved when accidents occur. Thus, it has become a significant standard used to evaluate the management. 
Environmental information is the most critical factor affecting the quality grades and safety of perishable products Based on various environmental media, stratification can keep an account of the information and provide a summary accordingly to obtain data forms with the time attribute according to media classification. Temperature-humidity information keeps a record of temperature and humidity data of the surroundings based on the time series of perishable products in the supply chain. Independent information is extracted according to such surrounding of environmental media as liquid and solid media during the freezing process. Information stratification can achieve the following functions: (1) a dynamic and real-time evaluation of the quality status of perishable products is conducted; (2) the quality of perishable products is predicted and the risk is evaluated according to the dynamic changes of the quality and environment to ensure that timely decisions are made; and (3) the analysis is conducted using the historical summary information of environmental data. Data mining is used to determine the change of product environment. On this basis, the effect of a certain period of dramatic environmental change on the quality of perishable products can be set as high-risk environmental phase. Through information correlation, environment and operation are connected to realize control of the key operation node, which can provide a reliable reference for process optimization.

Inspection-information stratification, the key of supplychain data, is the criterion in which perishable products can flow or smoothly circulate in supply-chain nodes. Stratification can realize the following functions: (1) symbolizes the smooth operation of each node in the supply chain, the standard used to determine if perishable products are in accordance with security requirements of the supply chain, and the important basis for determining if the products are qualified; (2) serves as the criterion for information tracking of perishable products, that is, marking an efficient circulation process from the source to the terminal of the supply chain; and (3) provides consumers with evidence that the perishable products are qualified.

The stratification of quality information is important for the quality evaluation of perishable products and can achieve real-time assessment and phase evaluation of quality. The stratification has the following functions: (1) Based on the summary of the stratification information, real-time assessments of perishable products are conducted by utilizing the quality evaluation model, which is the most reliable for dynamic decision-making and early warning. (2) Taking supply-chain nodes as the main body, the implementation of independent participants in the supply chain can be evaluated; whether these nodes can offer the most suitable environment for the circulation of perishable products can be determined, thereby providing a powerful evidence for overall optimization of the supply chain. (3) Real-time and dynamic quality ratings of perishable products are generated to implement dynamic price-making strategies as the reliable data support. (4) The flow of perishable products in the supply chain can be directed. According to its ranking, the values of different kinds of perishable products can be considerably realized to ensure effective control of costs. (5) The risk of implementation and operation in the supply chain can be identified in advance, and the shelf life of perishable products can be accurately predicted.

Based on the entire highly integrated supply-chain information, the preceding information presented, can be used to extract and handle the key information to accomplish the overall integration, optimization, and decision-making of the supply chain. Stratification has summarized and processed the most vital information which is handled by the supply chain. Based on the framework of information sharing, stratification can ensure safe operation, identify environmental risk, inspect information for corroboration, and evaluate quality, thereby providing important informational support for the overall optimization of the supply chain and the rational distribution of its resources. Stratification has filled the information gap between nodes in the supply chain, thus managing the supply chain and conducting overall decision-making.

\subsection{Model for determining the quality and safety of aquatic products}

The safety evaluation of aquatic product qualities is a kind of safety analysis and evaluation in the cold-chain process from the quality decay angle. The model is mainly the estimation of quality decay according to T-T-T Rules and Labuza Model.

The decision-making of aquatic product cold-chain information is defined and derived by $f(x)$. By setting $f(x)$ as the evaluation model of aquatic product qualities, the data of time-temperature attribute in cold-chain nodes can be extracted, thus obtaining the model of quality change and quality guarantee period. According to the time-temperature data of aquatic products in the processing and transporting, decision function is set to $f(x)=f(T, \theta)=A(T, \theta)$. Using T-T$\mathrm{T}$ and Labuza for reference and the proposed algorithm based on the Arrhenius Model, Formulas (1)-(6) are applied to analyze aquatic product qualities.

Quality evaluation of aquatic products is directly related to the fluctuation of cold-chain temperature. According to the fluctuation feature analysis, $\mathrm{f}(\mathrm{x})$, the evaluation model of aquatic product qualities is defined as follows: constant temperature in storage state; continuous temperature fluctuation in refrigeration and transportation; and times of door-opening and closing, which lead to state changes of the critical quality in the process of quick-freezing, cold storage, and freezing. The quality evaluation model of aquatic products is constructed to deal with the three temperature environments as follows.

Generally, aquatic products in storage have been placed for a prolonged period. The temperature of cold and freezing storage is usually set to $-18^{\circ} \mathrm{C}$, which can be regarded as the state of constant temperature. The model can be formulated by the following equations:

$$
\begin{aligned}
& f\left(A_{0}, \theta, T\right)=A_{0} \cdot \exp \left[-\sum k_{i} \theta_{i}\right] \\
& k_{i}=\frac{\ln A / A_{0}}{\theta_{s}}
\end{aligned}
$$

In Formulas (1) and (2), A0 is the quality parameter, with 1 as the initial quality (the best quality); $\mathrm{A}$ is the quality parameter in the current state; $\mathrm{k}$ is the Boltzmann constant, where temperature dependence is related to the constant which is subjected to the Arrhenius model; ki is the Boltzmann constant when the time is $\theta \mathrm{i}$; and $\theta_{s}$ is the overall reaction time.

The temperature environment of aquatic products in refrigeration and transportation is in a state of continuous fluctuation. In this state, quality decay is related to the 
quality of the initial state. The evaluation model of aquatic products, $f\left(A_{0}, \theta, T\right)$, is established as follows:

$$
\begin{aligned}
& f\left(A_{0}, \theta, T\right)=A_{0} \cdot \exp \left\{-\frac{1}{2} \cdot k_{T_{m}} \theta_{T}\left[Q_{10}{ }^{a}+Q_{10}{ }^{-a}\right]\right\} \\
& a=\left[\frac{T+10}{T+\Delta T}\right]
\end{aligned}
$$

where $\mathrm{A} 0$ is the quality parameter, with 1 as the initial quality (the best quality); $\mathrm{A}$ is the quality parameter in the current state; $\mathrm{k}$ is the Boltzmann constant, where temperature dependence is related to the constant which is subjected to the Arrhenius model; $k_{T_{m}}$ is the Boltzmann constant when the time is $T_{m} ; \mathrm{T}$ is the environmental temperature; $\Delta T$ is the amplitude of temperature fluctuation $\theta_{s}$ is the overall reaction time; $\mathrm{Q}_{10}$ is the temperature coefficient; and a is the temperature variation ratio.

The critical state of cold chain indicates that the temperature of aquatic products continuously fluctuates in the process of instant freezer, freezer, frozen storage, and refrigeration transport due to the discontinuous temperature fluctuation caused by door opening and closing of the warehouse compartment during loading and unloading. If the temperature dramatically changes within a week, then the quality will be affected to some extent. Aquatic products are inevitably in a continuous critical state of temperature fluctuation due to the circulation phases and numerous links in the cold chain, which can cause a rapid decline in quality. The model for defining the critical state of aquatic products is expressed as follows:

$$
\begin{aligned}
& f\left(A_{0}, \theta, T\right)= \\
& A_{0} \cdot \exp \left\{1+\frac{(\Delta T \cdot b)^{2}}{2^{2}}+\frac{(\Delta T \cdot b)^{4}}{2^{2} \cdot 4^{2}}+\frac{(\Delta T \cdot b)^{6}}{2^{2} \cdot 4^{2} \cdot 6^{2}}\right\} \\
& A=A_{0} \exp \left[-k_{T_{m}} \cdot \ln \frac{A}{A_{0}} \cdot \theta_{T}\right]
\end{aligned}
$$

where $A_{0}$ is the quality parameter, with 1 as the initial quality (the best quality); $\mathrm{A}$ is the quality parameter in the current state; $\mathrm{k}$ is the Boltzmann constant, where temperature dependence is related to the constant which is subjected to the Arrhenius model; $k_{T_{m}}$ is the Boltzmann constant when the time is in $T_{m} ; \mathrm{T}$ is the environmental temperature; $\Delta T$ is the amplitude of temperature fluctuation; and $b$ is the periodic function of temperature fluctuation.

The preceding models contribute to the quality evaluation effect of analysis and definition of the temperature fluctuation in the cold chain of aquatic products. The environment of temperature fluctuation where aquatic products are exposed is determined according to cold-chain information. On this basis, the evaluation model is selected accordingly to analyze and evaluate the safety of aquatic products. Therefore, in accordance with the safe states of aquatic products in cold chain, accurate decisions are made, and rapid response strategies are adopted.

\section{Result analysis and discussion}

\subsection{Description}

In this study, mackerel frozen fillet in the entire process of supply-chain circulation is taken as an example to carry out the overall collection and stratification of supply-chain information. Their responsibilities are supposed to be clarified and product information should be systematically correlated to ensure fish quality and its certain quality states within the stay-time in each node enterprise. Meanwhile, supply-chain information is managed by modularization.

The entire operation carries out modularization information management in this study to ensure that highquality mackerel is put into the market. During the process, the related data of enterprises, products, location, environment, and operation and the private data are collected and inputted into the system. The entry data can drive operations, such as fishing, transportation, processing, warehousing, distribution, and sales.

The management function in this mackerel case is the one with non-standard modularization information to ensure fish quality and its certain quality states within the stay-time in each node enterprise and clarify their responsibilities. To deal with it, data, including monitoring, location, risk, cost, and cooperation data, are collected and inputted into the management system. Driven by those data, quality monitoring, source tracking, information fusion, market forecasting, and other functions are realized. During the mackerel supply-chain management, standard and nonstandard modules are correlated, thereby jointly completing the overall control of supply chain based on modularization management.

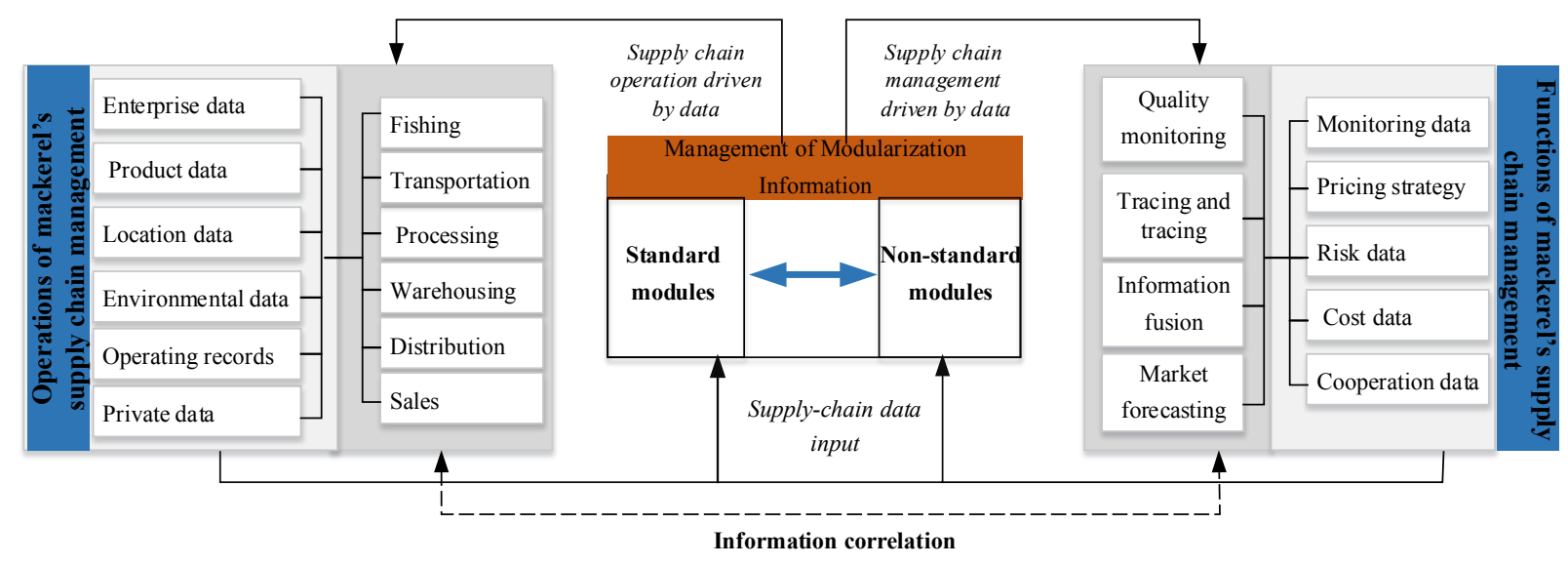

Fig. 5. Overall control of mackerel supply chain based on modularization management 
Mackerel is a typical perishable product. In this section, processing phase is exemplified to illustrate the control of information and precise information sharing in supply chain. Mackerel processing in cold chain is divided into 12 procedures. Strictly controlling the center temperature of the fish at different processing stages is necessary to ensure its quality and record relevant information. First, raw materials are half-thawed at the temperature ranging from $-6{ }^{\circ} \mathrm{C}$ to -8 ${ }^{\circ} \mathrm{C}$, followed by fish breaking, head cutting, and visceral cutting. Then, raw materials are thawed, and product temperature of regular raw materials is inspected and recorded according to corresponding data. Next, when the center temperature is between $-4{ }^{\circ} \mathrm{C}$ to $-7{ }^{\circ} \mathrm{C}$, the fish is divided into three pieces alongside and then cut in the middle. Between $-3{ }^{\circ} \mathrm{C}$ to $-5{ }^{\circ} \mathrm{C}$, the crescent bone is removed and the visceral is gutted and reshaped. Removal of the abdominal bone and cutting into several parts are performed at temperatures between $-2{ }^{\circ} \mathrm{C}$ and $-3{ }^{\circ} \mathrm{C}$. Pulling the fish is carried out between $-3{ }^{\circ} \mathrm{C}$ and $1{ }^{\circ} \mathrm{C}$. The temperature is maintained between $-3{ }^{\circ} \mathrm{C}$ and $5{ }^{\circ} \mathrm{C}$ after cleaning the fish. Soaking is performed between $-2{ }^{\circ} \mathrm{C}$ to 4.5 ${ }^{\circ} \mathrm{C}$. Furthermore, different parts of raw materials are placed and frozen at different temperatures. In this process, relevant records of quality control table, semi-finished product reworking, product temperature, foreign body examination, and electronic weighing are taken. Different processing temperatures are set according to the product in different phases, the quality is monitored according to corresponding records. Finally, changes in the quality at different temperatures can be analyzed, and cold chain of products can be optimized to improve the quality.

Apart from processing, fishing, transportation, and warehousing, other operation links in mackerel supply chain require strict control. After the analysis of every operation link, information modularization is designed to form the supply-chain modular structure.

Table 1. Processing flow and information recording of mackerel in supply chain

\begin{tabular}{|c|c|c|c|c|}
\hline No. & processing & Tools or machines & Product temperature & Recording \\
\hline 1 & half thawing raw materials & Thawing basin & \multirow[b]{3}{*}{ Center temperature of fish: $-6 \sim-8^{\circ} \mathrm{C}$} & \multirow{3}{*}{$\begin{array}{c}\text { Raw materials } \\
\text { thawing records } \\
\text { Product temperature } \\
\text { records } \\
\text { Regular raw materials } \\
\text { inspecting records }\end{array}$} \\
\hline 2 & breaking fish & hands & & \\
\hline 3 & Cutting the head and gutting the visceral & Chaff-cutter and awl & & \\
\hline \multirow{2}{*}{4} & Dividing the fish into three pieces & broach & \multirow{2}{*}{ Center temperature of fish: $-4 \sim-7^{\circ} \mathrm{C}$} & \multirow{7}{*}{ quality control table } \\
\hline & Cutting in the middle & Central cutting machine & & \\
\hline 5 & Removing the crescent bone & knife & \multirow{3}{*}{ Center temperature of fish: $-3 \sim-5^{\circ} \mathrm{C}$} & \\
\hline 6 & Gutting the visceral & ladle & & \\
\hline 7 & reshaping & knife & & \\
\hline \multirow[b]{2}{*}{8} & Removing the abdominal bone & knife & Center temperature of fish: $-2 \sim-3^{\circ} \mathrm{C}$ & \\
\hline & Cutting into pieces & knife & $\begin{array}{l}\text { Center temperature before fish freezing and } \\
\text { cutting: }-2 \sim-3^{\circ} \mathrm{C}\end{array}$ & \\
\hline 9 & Pulling the fish & tweezers & $\begin{array}{l}\text { Center temperature before pulling fish } \\
\text { pulling: }-3 \sim 1^{\circ} \mathrm{C}\end{array}$ & \multirow[t]{2}{*}{$\begin{array}{l}\text { Product temperature } \\
\text { records }\end{array}$} \\
\hline 10 & cleaning & Purge tank & $\begin{array}{l}\text { Center temperature before fish cleaning: }-3 \sim 5 \\
{ }^{\circ} \mathrm{C}\end{array}$ & \\
\hline 11 & soaking & Saltwater through & $\begin{array}{l}\text { Center temperature before fish soaking : -2 - } \\
4.5^{\circ} \mathrm{C}\end{array}$ & \multirow{2}{*}{$\begin{array}{c}\text { foreign body } \\
\text { examination records }\end{array}$} \\
\hline 12 & Placing and freezing & $\begin{array}{l}\text { IQF plate } \\
\text { IQF machine }\end{array}$ & $\begin{array}{l}\text { IQF machine temperature: }-40^{\circ} \mathrm{C} \\
\text { Center temperature of fish:- }-20^{\circ} \mathrm{C} \\
\text { three cutting slices: } \quad-2 \sim-4{ }^{\circ} \mathrm{C} \\
\text { the slice without bones: }-2 \sim 1^{\circ} \mathrm{C} \\
\text { the slice with low salt: } \quad 7 \sim 10^{\circ} \mathrm{C} \\
\text { cutting into pieces:-6 }-11^{\circ} \mathrm{C}\end{array}$ & \\
\hline
\end{tabular}

\subsection{Structural design of mackerel supply-chain information modularization}

Through previous analysis, the standard module of mackerel in the supply chain comprises the information of enterprises, real-time geographical location, products, and real-time environment. Non-standard module comprises operation, management, cost, and other private information.

(1) Standard module of enterprise information

Collecting and storing necessary information of enterprises are essential to the standard module formation of enterprise information to clarify the responsibilities of enterprises between nodes. The contents of this module are the major shared information in supply chain and the fundamental data to realize the complete and integrated supply-chain information. Table 2 shows that the standard module of enterprise information has informational structures, such as basic information, starting position of supply-chain nodes, and shared information range. The basic information contains the key information on disclosed relevant node-enterprises, such as legal corporate information and global location code. The starting position data of supply-chain nodes are mainly used to determine supply-chain location of enterprises to clarify the production, processing, and service that different enterprises are engaged in. Shared information range oversees the provision of information-sharing service for external enterprises to ensure that integrated supply-chain information can utilize shared information.

(2) Standard module of product information

Node enterprises will monitor the products and collect and store relevant information to ensure quality mackerel products within residence time inside enterprises. Hence, mackerel supply-chain information in the entire process is in part and invisibly stored in different databases of node enterprises. This also clarifies the two following points. On the one hand, when the product information of supply chain may be comprehensively collected, relevant node enterprises 
have already completely saved the information in a relative degree; on the other hand, this kind of information is stored in several different databases. The standard module of product information will integrate this kind of decentralized information for sharing and utilizing of the entire supply chain. Table 2 shows that the standard module of product information includes processing, mackerel quality description/image, quality evaluation, inspection, and quarantine results of mackerel. When the mackerel shape changes after processing or packaging (such as mackerel processing from an entire fish to pieces), closely correlating the product information is necessary before and after the change to ensure the completeness of the aquatic product information.

Table. 2. Mackerel supply-chain standard module

\begin{tabular}{|c|c|c|c|c|c|}
\hline Module & \multicolumn{2}{|c|}{ Information structure } & Module & \multicolumn{2}{|c|}{ Information structure } \\
\hline \multirow{10}{*}{ 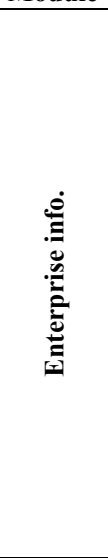 } & \multirow{3}{*}{ Basic information } & Global location number & \multirow{10}{*}{$\frac{\stackrel{0}{\Xi}}{\stackrel{\Xi}{E}}$} & \multirow{2}{*}{ Mackerel processing } & Processing codes \\
\hline & & Enterprise number & & & Name of processing \\
\hline & & Legal Corporate Info & & \multirow{3}{*}{$\begin{array}{l}\text { Status description of } \\
\text { Mackerel's quality }\end{array}$} & $\begin{array}{l}\text { product description of } \\
\text { Mackerel }\end{array}$ \\
\hline & \multirow{5}{*}{$\begin{array}{l}\text { starting position of } \\
\text { supply-chain }\end{array}$} & 01 processing & & & $\begin{array}{l}\text { production image of } \\
\text { Mackerel }\end{array}$ \\
\hline & & 02 Wholesale distribution & & & $\begin{array}{l}\text { status description of } \\
\text { Mackerel }\end{array}$ \\
\hline & & 03 retailing & & \multirow{2}{*}{ Quality evaluation } & Mackerel sales or not \\
\hline & & 04 warehousing & & & Product freshness \\
\hline & & 05 transportation & & \multirow{3}{*}{$\begin{array}{l}\text { inspection and quarantine } \\
\text { results of mackerel }\end{array}$} & $\begin{array}{l}\text { Name of inspection and } \\
\text { quarantine report }\end{array}$ \\
\hline & \multirow{2}{*}{$\begin{array}{l}\text { Shared } \\
\text { information range }\end{array}$} & Shared information flow range & & & Test results \\
\hline & & $\begin{array}{l}\text { Accessible enterprise authorization } \\
\text { info }\end{array}$ & & & Date of report \\
\hline \multirow{8}{*}{ 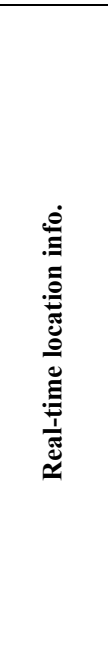 } & \multirow{2}{*}{$\begin{array}{c}\text { Real-time } \\
\text { longitude and } \\
\text { latitude }\end{array}$} & Enterprise number & \multirow{8}{*}{ 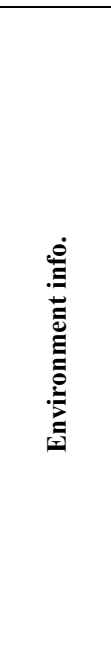 } & \multirow{2}{*}{ Environment attribute } & $\begin{array}{l}\text { Environment attribute } \\
\text { number }\end{array}$ \\
\hline & & Real-time longitude and latitude & & & Environment condition \\
\hline & \multirow{4}{*}{ Node description } & $\begin{array}{l}\text { Processing/ } \\
\text { Wholesale distribution/ } \\
\text { Retailing/ } \\
\text { Warehousing/ } \\
\text { Transportation/ }\end{array}$ & & \multirow[b]{2}{*}{ Time-T-H info } & $\begin{array}{l}\text { Real-time humidity } \\
\text { monitoring /Processing/ } \\
\text { Wholesale distribution/ } \\
\text { Retailing/Warehousing/ } \\
\text { Transportation }\end{array}$ \\
\hline & & Total records of operation & & & $\begin{array}{l}\text { Real-time temperature } \\
\text { monitoring/Processing/ } \\
\text { Wholesale distribution/ } \\
\text { Retailing/Warehousing/ } \\
\text { Transportation }\end{array}$ \\
\hline & & Name of N-operation & & \multirow{4}{*}{$\begin{array}{l}\text { Environment info } \\
\text { description /image }\end{array}$} & Environment Description \\
\hline & & N-operation number & & & Environment image \\
\hline & \multirow{2}{*}{ Residence time } & Residency time of $\mathrm{N}$-operation & & & Environment image \\
\hline & & Total residence time of nodes & & & description \\
\hline
\end{tabular}

(3) Standard module of real-time location information

Predicting the time for mackerel to reach the final sales cycle and estimating its quality status are necessary. Tracking real-time logistics location of mackerel in the supply chain and ascertaining its residence time in each operation link of each node enterprise are also necessary. Through these methods, mackerel quality at a point of time can correspond to its stay. In Table 2, the standard module of location information contains real-time longitude and latitude, node description, and residence time. The real-time longitude and latitude can precisely identify the exact location of mackerel. Moreover, real-time longitude and latitude correspond to the starting position of supply chain, which can mark the location of mackerel in the supply chain. Node description can reconfirm mackerel location and offer specific operational links in the supply chain. Time and space are inseparable in location information which must be accompanied by time information. The residence time data collection not only can supplement the location time but also reflect the proportion of the time spent by each node enterprise in the mackerel supply chain to the time consumed in the entire circulation.

(4) Standard module of environmental information
The standard module of environmental information refers to the process where mackerel has gone through several node enterprises in the supply chain, from being fished to being served to consumers. More importantly, every single operational link can change its storage conditions of mackerel, which inevitably influences its quality, thus directly influencing mackerel quality and its shelf-life period. Hence, monitoring the environment of the entire supply chain is significant to ensure fish quality. The standard module of environmental information is constructed by environmental attribute, time-temperature and humidity information, and description/image of environment information. Temperature and humidity information can reflect the temperature and humidity situation where mackerel is in at any time in any link. Description/image of environment information represents the information, except for temperature and humidity, such as packing and hygienic condition.

Any supply chain has non-standard information data and enterprises have private information that is not shared. According to the features of mackerel in cold-chain operation, four non-standard modules, such as operation information, management information, cost information, and 
other private information, are designed to meet the needs of different supply-chain node enterprises and deal with unshared information.

(5) Standard module of private information

The non-standard module mainly serves as an internal management necessary for different node enterprises of mackerel supply chain. This module can also support enterprises to add the information-sharing function according to quality management and control of the mackerel and supplement and improve the supply-chain information integration. Table 3 shows that this module contains non-standard module of operation information, management information, cost information, and other private information. The information correlation in the operation module links each standard module and supports the information integration of the mackerel product. The management information module mainly supports and records the internal management operation of the enterprise and assists enterprises in managing and controlling the quality level and delivery of mackerel products within the enterprise. Cost module mainly provides support to the enterprise to record operational costs of mackerel in supply chain, thereby providing decision-makers with real-time financial cost data. Other private information modules allow the enterprise to design connections to its internal information system and record access.

Table 3. Non-standard module of mackerel supply-chain

\begin{tabular}{|c|c|c|c|c|c|}
\hline Module & & Information structure & Module & & nformation structure \\
\hline \multirow{7}{*}{ 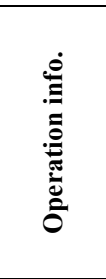 } & \multirow{4}{*}{$\begin{array}{l}\text { Correlation } \\
\text { info. }\end{array}$} & Processing codes & \multirow{7}{*}{ 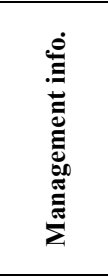 } & \multirow{3}{*}{ Baisc info. } & Principle Number \\
\hline & & Environment info NO. & & & Management Module Number \\
\hline & & Location info No. & & & Operational link NO. \\
\hline & & $\begin{array}{l}\text { starting position of supply-chain } \\
\text { node }\end{array}$ & & \multirow{4}{*}{ Flow Control Info. } & Environmental Quality Inspector NO. \\
\hline & \multirow{3}{*}{$\begin{array}{l}\text { Operation } \\
\text { records }\end{array}$} & Operator Info & & & Product Quality Inspector No. \\
\hline & & Operation info records & & & Flow Control code \\
\hline & & Examination and Audit Results & & & Description of flow-control results \\
\hline \multirow{5}{*}{ 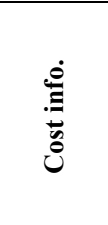 } & \multirow{2}{*}{ Basic info. } & Cost Types & \multirow{5}{*}{ 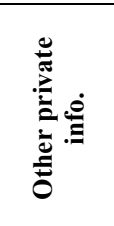 } & \multirow{2}{*}{$\begin{array}{c}\text { Documental } \\
\text { records }\end{array}$} & Access records \\
\hline & & Accounting Number & & & System documents \\
\hline & \multirow{3}{*}{ Finance } & Accounting Document Number & & \multirow{3}{*}{ System access } & ERP \\
\hline & & Production cost & & & EDI \\
\hline & & Management cost & & & WMS \\
\hline
\end{tabular}

From the preceding discussion, the non-standard module is designed to meet relevant functions necessary for node enterprises. During the process of mackerel supply-chain quality management and control, enterprises can utilize the non-standard module to take information, thus achieving dynamic connection to the standard module when detailed and relatively private information is needed to offer service. The specifics are enumerated herein to provide a good description of the correlation between standard and nonstandard modules.

\subsection{Establishing data relations}

According to the correlation between standard and nonstandard modules and the structural design of information modularization of mackerel in the supply chain, data correlation is constructed as shown in Fig. 6. In the diagram, non-standard module of operation information works as the confection to other modules for enterprises. In other words, via different structure numbers in the non-standard module of operation information, each part of the standard and the non-standard module can be connected to realize the indepth data integration of mackerel in the supply chain in the vertical direction (for example, a few specific operations can be tracked). The information of each standard module is shared in the entire supply chain of mackerel to realize data integration in the horizontal direction; that is, using the standard module of environmental information for quality monitoring.

Enterprises can conveniently take such private information of non-standard module as cost and management as supplementary information through the nonstandard module of operation information. In addition, each non-standard module certainly establishes the correlation by which access to relevant standard modules is directly provided to help enterprises better manage the shared information of mackerel products and obtain the shared information of other node enterprises.

\subsection{Information comparison}

In this study, the multi-level, multi-dimension management model for perishable products in the supply chain is applied to the entire mackerel supply-chain process of Oriental Oceanic Corporation. The data collected is compared with those from the traditional supply-chain management mode (Diagram 7). The data collected in the traditional mode evidently suffered worse data fault. Accurately predicting the shelf-life period of mackerel or precisely controlling the risk due to perishable products in the supply chain is not conducive.

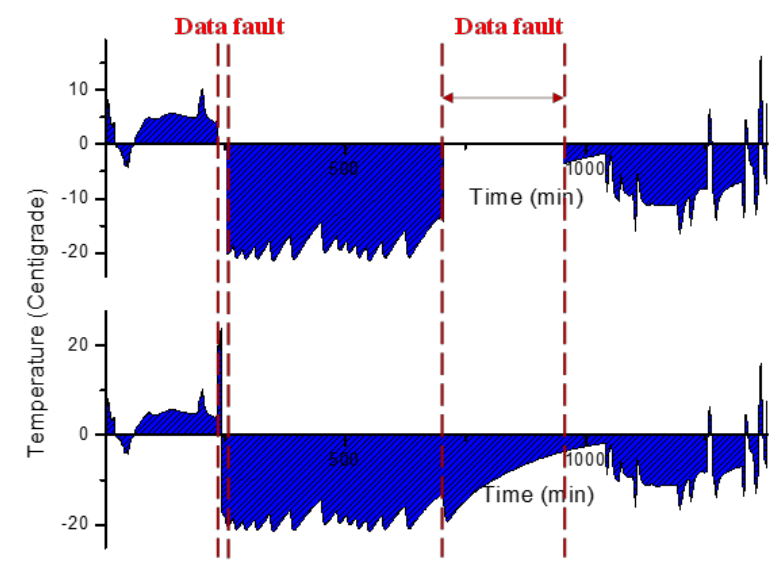

Fig. 7. Temperature data collection and comparison 


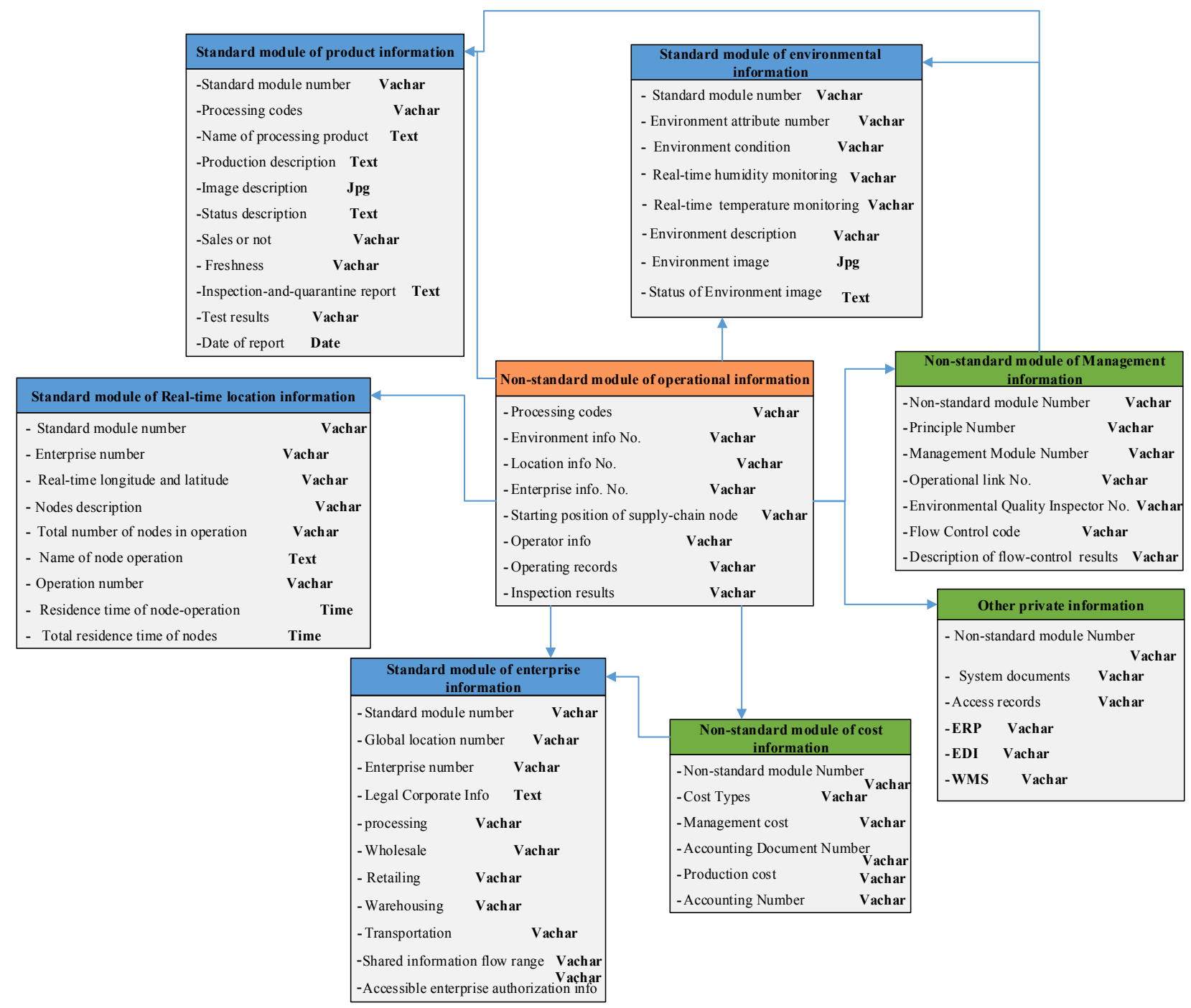

Fig. 6. Data correlation diagram

Meanwhile, other technical parameters in the traditional mode are compared with those based on information stratification in this study. As shown in Diagram 8, regarding parameters, such as accuracy, integrity, operational description, temperature, and coverage, the traditional mode is poor compared to the management mode proposed in this study when it comes to the information control and management of the entire supply chain of perishable products.

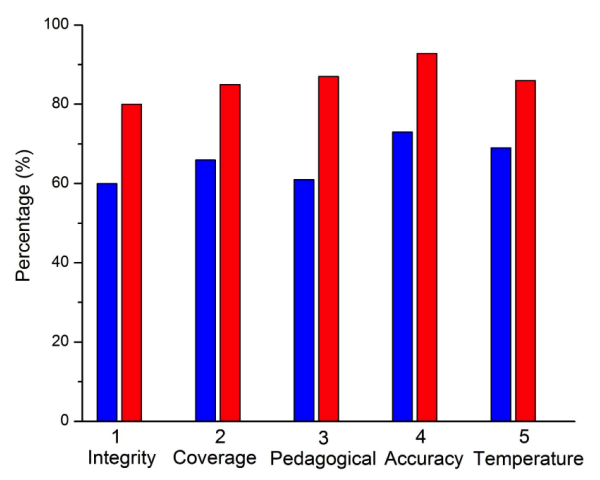

Fig. 8. Comparison between supply-chain management mode and traditional mode in perishable products

\section{Conclusions}

To realize the complete collection and integration of perishable product supply-chain information and reveal the influence of environmental factors on the quality of perishable products, this study defined information recording in the entire circulation of perishable product by adopting independent information modularization and dynamic information stratification to record and conduct the supplychain information processing of perishable products. Moreover, taking the aquatic product as an example to carry out the experiment of the entire cold-chain information collection, the following conclusions are drawn:

(1) The supply chain of perishable products, which can effectively and efficiently connect all supply-chain information in the entire circulation to obtain $20 \%$ information integration, has been independently modularized (2) A high information integration level leads to accurate risk identification and control. Utilizing independent modularization could improve the risk identification rate by $25 \%$ in the supply chain of perishable products.

(3) Independent modular processing of the supply chain could reduce quality decay of perishable products through timely management of risk identifications, thereby increasing precise shelf-life estimation by $15 \%$. 
This study proposed a model where multi-dimensional information modularization of perishable product supply chain could be dynamically processed by combining the theoretical research with practical situation. This model had certain reference points for safe and proper management of modern perishable product supply chain. Owing to insufficient data result analysis from the supply-chain modular processing, combining multi-dimensional information modularization with this model and providing improvements in the future research can enhance the feasibility of supply-chain modularization, thus increasing social and economic benefits in real life.

\section{Acknowledgements}

This work was supported by the Colleges and universities of Shandong province science and technology plan projects No. J16LE16) and the Natural Science Foundation of Shandong Province (ZR2017BG016 and ZR2015PE010).

This is an Open Access article distributed under the terms of the Creative Commons Attribution Licence

\section{References}

1. Ju Chia, K., Mu-Chen, C., "Developing an advanced MultiTemperature Joint Distribution System for the food cold chain". Food Control, 21, 2010, pp.559-566.

2. Hongfeng, X., Hua, Z., Yanmin, Z., "Research status and future development trend of cold chain logistics". Ecological Economy, 5, 2012, pp.141-143, 150

3. Whitin, T. M., "Theory of inventory management". US: Princeton University Press, US, 1957, pp.5-7.

4. Nahmias, S., "Perishable inventory theory: a review". Operation Research, 30(4), 1982, pp.680-708.

5. Yu-yi, C., Yao-jen, W., Jinn-ke, J., “A novel deployment of smart cold chain system using 2G-RFID-Sys". Journal of Food Engineering, 141(5), 2014, pp.113-121.

6. Carol, W., "Food safe assurance systems: hazard analysis and critical control point system (HACCP): principles and practice". Encyclpedia of Food Safety, 4, 2014, pp.226-239.

7. Speier, C., Whipple, J. M., Closs, D. J., Voss, M. D., "Global supply chain design considerations: Mitigating product safety and security risks". Journal of Operations Management, 29, 2011, pp.721-736.

8. Prakash, G., PravinRenoldb, A., Venkatalakshmi, B., "RFID based Mobile Cold Chain Management System for Warehousing". Procedia Engineering, 38, 2012, pp.964-969.

9. Gustavsson, J., Cederberg, C., Sonesson, U., "Global Food Losses and Food Waste". Worlds Agriculture Forestry \& Fisheries, 27, 2011, pp.9-14.

10. David, B., Marija B., Domen H., "Mitigating risks of perishable products in the cyber-physical systems based on the extended MRP model". International Journal of Production Economics, 193, 2017, pp.51-62.

11. Rasmus, H., Patrick, D., Marius, V., Michael, L., "Reducing food losses and carbon emission by using autonomous control-a simulation study of the intelligent container". International Journal of Production Economics, 164, 2015, pp.400-408.
12. Yahia, E. M., "Modified and Controlled Atmospheres for the Storage, Transportation, and Packaging of Horticultural Commodities". US: CRC Press, US, 2010, pp. 608-610.

13. Jedermann, R., Nicometo, M§§., Uysal, I., Lang, W., "Reducing food losses by intelligent food logistics". Philosophical Transactions of The Royal Society A, 372, 2018, pp1-20.

14. Sievers, S., Seifert, T., Schembecker, G., Bramsiepe, C., "Methodology for evaluating modular production concepts". Chemical Engineering Science, 155, 2016, pp.153-166.

15. Kern, W., Lämmermann, H., Bauernhansl, T., "An Integrated Logistics Concept for a Modular Assembly System”. Procedia Manufacturing, 11, 2017, pp.957-964.

16. Shoval, S., Efatmaneshnik, M., Ryan, M. J., "Probabilistic Approach to Modular Assembly". IFAC-PapersOnLine, 50(1), 2017, pp.5688-5693.

17. Kristianto, Y., Helo, P., "Product architecture modularity implications for operations economy of green supply chains". Transportation Research Part E: Logistics and Transportation Review, 70, 2014, pp.128-145.

18. Rossi, F., Manenti, F., Reklaitis, G., "A general modular framework for the integrated optimal management of an industrial gases supply-chain and its production systems". Computers \& Chemical Engineering, 82(2), 2015, pp.84-104.

19. Tanash, M., Contreras, I., Vidyarthi, N., "An exact algorithm for the modular hub location problem with single assignments". Computers \& Operations Research, 85, 2017, pp.32-44.

20. Kaczmarek, S., Mosblech, C., Lier, S., Ten Hompel, M., "Modularisierung und automatische Anordnungs-planung der Intralogistik fü $r$ modulare Container-anlagen in der Prozessindustrie". Chemie Ingenieur Technik-CIT, 87(9), 2015, pp.1246-1257. 